\title{
Regional Distribution of Pulmonary \\ Ventilation and Perfusion in Elderly Subjects
}

\author{
J. Holland, J. Milic-Emil, P. T. Macklem, and D. V. Bates \\ From the Joint Cardio-Respiratory Service, Royal Victoria Hospital and \\ the Department of Physiology, McGill University, Montreal, Canada
}

A в S T R A C T Using radioactive xenon, we measured the regional distribution of pulmonary ventilation and blood flow in six normal men, whose ages ranged between 65 and $75 \mathrm{yr}$. The measurements were made in the standing position. The static volume-pressure relation of the lungs was also measured in five of the subjects. The results indicate that by comparison with normal young men: (a) Blood flow to the upper lung zones was increased, although it still remained predominant in the lower zones. (b) Ventilation distribution during a vital capacity inspiration was similar to that seen in young subjects. (c) In five of the six elderly subjects, however, the distribution of ventilation in the resting tidal volume range was not preferential to the lower zones as it was in young men. This was probably caused by airway closure in the lower lung zones. The elderly subjects thus exhibit during normal tidal volume breathing a ventilation distribution pattern similar to that observed in young subjects when breathing at low lung volumes, i.e., near residual volume. This difference is probably due to the combined effect of the loss in elastic recoil of the lungs observed in the elderly subjects and of a decreased resistance to collapse of the aged airways. These findings suggest that in the elderly subjects there is a significant regional ventilation-perfusion impairment during quiet breathing, which may explain in part

Dr. Holland's present address is Cardio-Pulmonary Laboratory, Dalhousie University, Halifax, Canada. Address requests for reprints to Dr. J. Milic-Emili, Department of Physiology, McGill University, Montreal 2, Canada.

Received for publication 9 August 1967 and in revised form 27. September 1967. the reported increase in alveolar-arterial oxygen difference with advancing age.

\section{INTRODUCTION}

Recent studies with radioactive xenon have shown that when a normal young subject takes a breath from resting lung volume, ventilation is distributed preferentially to the lower lung zones $(1-4)$. This behavior has been attributed to the combined effect of $(a)$ the "gradient" in pleural pressure down the lung and $(b)$ the static volume-pressure relation of the lungs (4). A number of workers, using a variety of techniques, have demonstrated that there is a vertical "gradient" of pleural pressure, with the more negative values at the upper parts (5-8). As a result, at resting lung volume the upper lung units are more expanded than those in the dependent zones (4). Furthermore, the more distended units at the lung top are situated on a flatter (less compliant) part of their static volumepressure curve than the smaller units at the bottom. Therefore, when a breath is taken from functional residual capacity (FRC), the difference in compliance between the upper and dependent parts of the lungs favors greater ventilation in the lower lung zones.

If breathing takes place at low lung volume, i.e. near residual volume, the distribution pattern of ventilation is entirely different, the upper lung units being better ventilated than those in the dependent zones (4). This reversal of ventilation distribution has been attributed to airway closure (trapping) in the dependent lung zones $(4,9)$. For closure to occur, pleural pressure must be 
greater than airway pressure (10). As lung volume approaches residual volume $(\mathrm{RV})$, the pleural pressure in the lower lung zones indeed exceeds airway pressure, causing trapping in the dependent lung zones. If then a small breath is inspired, the trapped units in the lower lung regions do not receive any of the inspired air; consequently, the inspired air is delivered predominantly to the upper lung regions.

In normal young subjects airway closure in the dependent lung zones is present only at lung volumes below the functional residual capacity (4, 9 ). With increased age, however, the lung volume at which the airways close would be expected to increase because the lungs of elderly subjects lose elastic recoil (11). Hence, pleural pressure in the lower lung zones will exceed airway pressure at lung volumes higher in elderly subjects than in young subjects. Furthermore, with aging the transpulmonary pressure at which the airways begin to close may be increased. Conceivably, therefore, in old age lower zone airway closure may be present even in the normal tidal volume range, and consequently ventilation to the lower lung zones will be reduced. Pulmonary blood flow, on the other hand, presumably would remain preferential to the lower lung zones, and thus the lower zones of elderly subjects might have reduced ventilation in relation to their perfusion. If so, the reported increase in alveolar-arterial oxygen difference in aged subjects $(12,13)$ might be caused, at least in part, by a ventilation-perfusion impairment on a regional basis.

To test this hypothesis we have used ${ }^{133} \mathrm{Xe}$ to measure the regional distribution of pulmonary ventilation and perfusion in six subjects whose age ranged from 65 to $75 \mathrm{yr}$. We also measured the static volume-pressure relationship of the lung to determine whether the elastic properties of the aged lungs accounted for the ventilation distribution.

\section{METHODS}

Six elderly men, all of whom were former hospital employees, volunteered as subjects for this study after the nature and purpose had been explained to them. None of these men had a history of chronic cardiac or respiratory disease; physical, electrocardiographic, and radiological examinations showed no significant abnormalities. Their physical characteristics and pulmonary function data are given in Table I. Vital capacity and expiratory reserve volume were measured in the standing posi- tion with a 9 liter Collins spirometer. Residual volumes were measured in subjects sitting upright in a body plethysmograph (14) and were slightly above the predicted normal data which had been derived from gas dilution measurements. Residual volume (which remains the same in sitting as in standing position) was added to the vital capacity and to the expiratory reserve volume to obtain the standing total lung capacity and the functional residual capacity. The maximal midexpiratory flow rate (MMFR) was slightly reduced in subjects P.G. and L.C. but the mean for the group as a whole was close to the predicted value. Four of the subjects had been cigarette smokers for considerable periods of time, and two had been nonsmokers. However, the group has been considered homogeneous since on the basis of pulmonary function tests and subsequent ventilation distribution data there was no reason to distinguish between the two nonsmokers and the four smokers. (As will be mentioned later, subject F.D., who had been a moderate smoker for $40 \mathrm{yr}$, had pulmonary function data which suggested that his lung had aged less than those of other subjects.)

Ventilation distribution was studied by the method described by Dollfuss et al. (9). Seven scintillation counters were positioned behind the right lung in a vertical line. These counters were fitted with rectangular lead collimators $14 \mathrm{~cm}$ long, with a frontal slit $2 \mathrm{~cm}$ high and $10 \mathrm{~cm}$ across. Counter positions relative to lung top were determined from chest radiographs. All measurements were made in the standing position. After careful positioning in front of the counters, the subject expired to residual volume (RV) and was switched into a spirometer circuit containing room air. He then inspired to total lung capacity (TLC) over a period of about $10 \mathrm{sec}$. At some preset inspiratory volume a $2-4 \mathrm{ml}$ bolus containing about $1 \mathrm{mc}$ of ${ }^{189} \mathrm{Xe}$ was automatically delivered into the inspirate near the mouth. Breath was held at full inspiration until stable count rates over the chest were achieved $(6-8 \mathrm{sec})$. The subject then performed a maximal expiration over a $10-15$ sec period, while ${ }^{139} \mathrm{Xe}$ activity (count rate) in expired gas was continuously measured with a scintillation counter placed near the mouth. We recorded the output from this counter (fed through a digital rate meter with a counting interval of $0.05 \mathrm{sec})$ together with expired volume on an $\mathrm{X}-\mathrm{Y}$ recorder. Six to nine bolus experiments were performed on each subject, varying the lung volume at which the bolus was inhaled. After each maneuver ${ }^{188} \mathrm{Xe}$ was washed out of the lungs until chest count rates had returned to background levels. Then the subject breathed again into a closed spirometer circuit containing a trace amount of ${ }^{139} \mathrm{Xe}$ in the air. At equilibration, the ratio of intrapulmonary ${ }^{183} \mathrm{Xe}$ concentration to external chest count rate was determined at TLC for each counter. This measurement enabled the external count rate to be converted to concentration of ${ }^{180} \mathrm{Xe}$ in each region, as described previously $(2,4)$. In these experiments the total lung capacities of the subjects were different, and the amount of ${ }^{183} \mathrm{Xe}$ inspired in each test varied. To facilitate comparison the results are expressed as a percentage of the concentration that would have existed had the inspired 
TABLE I

Physical Characteristics and Results of Pulmonary Function Tests of Six Elderly Subjects

\begin{tabular}{|c|c|c|c|c|c|c|c|c|c|c|c|c|c|}
\hline & Age & Height & Weight & Tobacco & $\mathrm{VC}$ & FRC & $R V$ & TLC & ME & $\begin{array}{c}\mathrm{FEV}_{0.75} \\
\times 40\end{array}$ & MMFR & DLCO & Pelmax \\
\hline & $y r$ & $\mathrm{~cm}$ & $k g$ & & \multicolumn{4}{|c|}{ liter } & $\%$ & $\begin{array}{l}\text { liter/ } \\
\text { min }\end{array}$ & $\begin{array}{l}\text { liler/ } \\
\text { sec }\end{array}$ & $\begin{array}{c}m l \text { of } \mathrm{CO} \\
\text { per min' } \\
m m \mathrm{Hg}\end{array}$ & $\mathrm{Cm} H: O$ \\
\hline E.B. & 70 & 165 & 77 & None & $\begin{array}{c}4.1 \\
(3.1)\end{array}$ & $\begin{array}{c}3.6 \\
(3.2)\end{array}$ & $\begin{array}{c}2.7 \\
(2.2)\end{array}$ & $\begin{array}{c}6.8 \\
(5.3)\end{array}$ & $\begin{array}{c}49 \\
(45)\end{array}$ & $\begin{array}{c}66 \\
(70)\end{array}$ & $\begin{array}{c}1.5 \\
(2.5)\end{array}$ & $\begin{array}{c}20.3 \\
(10.6)\end{array}$ & 20.0 \\
\hline L.B. & 70 & 162 & 73 & $\begin{array}{l}20 / \text { day } \\
\times 50 \text { yr }\end{array}$ & $\begin{array}{c}3.3 \\
(3.1)\end{array}$ & $\begin{array}{c}3.4 \\
(3.2)\end{array}$ & $\begin{array}{c}3.1 \\
(2.2)\end{array}$ & $\begin{array}{c}6.4 \\
(5.3)\end{array}$ & $\begin{array}{c}39 \\
(45)\end{array}$ & $\begin{array}{c}82 \\
(70)\end{array}$ & $\begin{array}{c}2.9 \\
(2.5)\end{array}$ & $\begin{array}{c}19.1 \\
(10.6)\end{array}$ & 28.0 \\
\hline K.D. & 75 & 178 & 89 & None & $\begin{array}{c}3.9 \\
(4.1)\end{array}$ & $\begin{array}{c}2.8 \\
(3.9)\end{array}$ & $\begin{array}{c}2.3 \\
(2.6)\end{array}$ & $\begin{array}{c}6.2 \\
(6.7)\end{array}$ & $\begin{array}{c}51 \\
(42)\end{array}$ & $\begin{array}{l}104 \\
(83)\end{array}$ & $\begin{array}{c}3.4 \\
(2.8)\end{array}$ & $\begin{array}{c}15.1 \\
(10.0)\end{array}$ & 25.0 \\
\hline F.D. & 66 & 166 & 78 & $\begin{array}{l}10 / \text { day } \\
\times 40 \mathrm{yr}\end{array}$ & $\begin{array}{c}3.5 \\
(3.1)\end{array}$ & $\begin{array}{c}3.4 \\
(3.2)\end{array}$ & $\begin{array}{c}2.5 \\
(2.2)\end{array}$ & $\begin{array}{c}6.0 \\
(5.3)\end{array}$ & $\begin{array}{c}63 \\
(48)\end{array}$ & $\begin{array}{l}112 \\
(72)\end{array}$ & $\begin{array}{c}3.7 \\
(2.5)\end{array}$ & $\begin{array}{c}21.2 \\
(11.8)\end{array}$ & 34.0 \\
\hline P.G. & 67 & 170 & 73 & $\begin{array}{l}5 / \text { day } \\
\times 45 \text { yr }\end{array}$ & $\begin{array}{c}3.5 \\
(3.4)\end{array}$ & $\begin{array}{c}4.1 \\
(3.5)\end{array}$ & $\begin{array}{c}3.2 \\
(2.3)\end{array}$ & $\begin{array}{c}6.7 \\
(5.8)\end{array}$ & $\begin{array}{c}31 \\
(48)\end{array}$ & $\begin{array}{c}63 \\
(75)\end{array}$ & $\begin{array}{c}1.5 \\
(2.6)\end{array}$ & $\begin{array}{c}21.0 \\
(11.5)\end{array}$ & 23.0 \\
\hline L.C. & 65 & 173 & 76 & $\begin{array}{l}30 / \text { day } \\
\times 40 \mathrm{yr}\end{array}$ & $\begin{array}{c}3.4 \\
(3.8)\end{array}$ & $\begin{array}{c}3.2 \\
(3.7)\end{array}$ & $\begin{array}{c}2.4 \\
(2.5)\end{array}$ & $\begin{array}{c}5.8 \\
(6.2)\end{array}$ & $\begin{array}{c}49 \\
(49)\end{array}$ & $\begin{array}{c}90 \\
(79)\end{array}$ & $\begin{array}{c}1.9 \\
(2.7)\end{array}$ & $\begin{array}{c}13.2 \\
(12.0)\end{array}$ & \\
\hline Mean & 68.8 & 169 & 77.6 & - & $\begin{array}{c}3.6 \\
(3.4)\end{array}$ & $\begin{array}{c}3.4 \\
(3.4)\end{array}$ & $\begin{array}{c}2.7 \\
(2.3)\end{array}$ & $\begin{array}{c}6.3 \\
(5.8)\end{array}$ & $\begin{array}{c}47 \\
(45)\end{array}$ & $\begin{array}{c}86 \\
(75)\end{array}$ & $\begin{array}{c}2.5 \\
(2.6)\end{array}$ & $\begin{array}{c}18.2 \\
(11.1)\end{array}$ & 26.0 \\
\hline
\end{tabular}

Abbreviations: VC, vital capacity; FRC, functional residual capacity; RV, residual volume; TLC, total lung capacity ; $\mathrm{ME}$, closed-circuit helium equilibration index; $\mathrm{FEV}_{0.75} \times 40$, indirect estimate of maximal breathing capacity obtained by multiplying the $0.75 \times$ sec forced expiratory value by 40 ; M MFR, maximal midexpiratory flow rate; DLCO, steady-

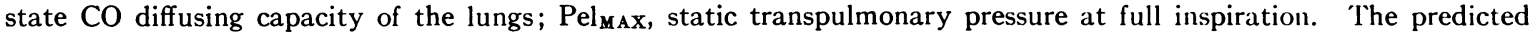
normal values of pulmonary function tests (15) are in parentheses beneath the measured values.

xenon been distributed uniformly within the lungs (2). Since all measurements were made at TLC, this ratio reflects ventilation "per alveolus" as described by Anthonisen and Milic-Emili (16).

The regional distribution of perfusion was determined by rapidly injecting $1-2 \mathrm{mc}$ of ${ }^{183} \mathrm{Xe}$ dissolved in $5 \mathrm{ml}$ of saline through a polyethylene catheter inserted into an antecubital vein. The injections were made at FRC, while the subject held his breath with open glottis until stable chest count rates were recorded (about $15 \mathrm{sec}$ ). This was followed by maximal inspiration of room air, and the subject held his breath at TLC until stable chest count rates were obtained (about $10 \mathrm{sec}$ ). Duplicate measurements were made in each subject. The results are expressed as distribution of perfusion "per alveolus," calculated according to the method of Anthonisen and Milic-Emili (16).

Measurements of the static volume-pressure relationship of the lungs were made on all subjects except L.C. with the esophageal balloon technique previously described (17). Both inflation curves from RV and deflation curves from TLC were measured.

\section{RESULTS}

Ventilation distribution. Fig. 1 illustrates the regional distribution of six boluses delivered at different lung volumes in subject L.B. When the bolus was inhaled at low lung volumes ( 0 and $11 \% \mathrm{VC})$; the regional ${ }^{133} \mathrm{Xe}$ concentration increased up the lung with a maximum at a distance of about $10 \mathrm{~cm}$ from lung top; at $21 \% \mathrm{VC}$ the differences in regional ${ }^{133} \mathrm{Xe}$ concentration became less marked ; at $36 \%$ VC the ${ }^{133} \mathrm{Xe}$ concentration increased progressively from lung top to bottom, the distribution being essentially the same whether the bolus was given at $36 \% \mathrm{VC}$ or at higher volumes. Similar distribution patterns were obtained in all subjects studied. The average results in the six elderly subjects are shown in Fig. 2A, where the regional ${ }^{133} \mathrm{Xe}$ concentration is plotted against the lung volume at which the bolus was inhaled (expressed as per cent of TLC). Results are pre- 


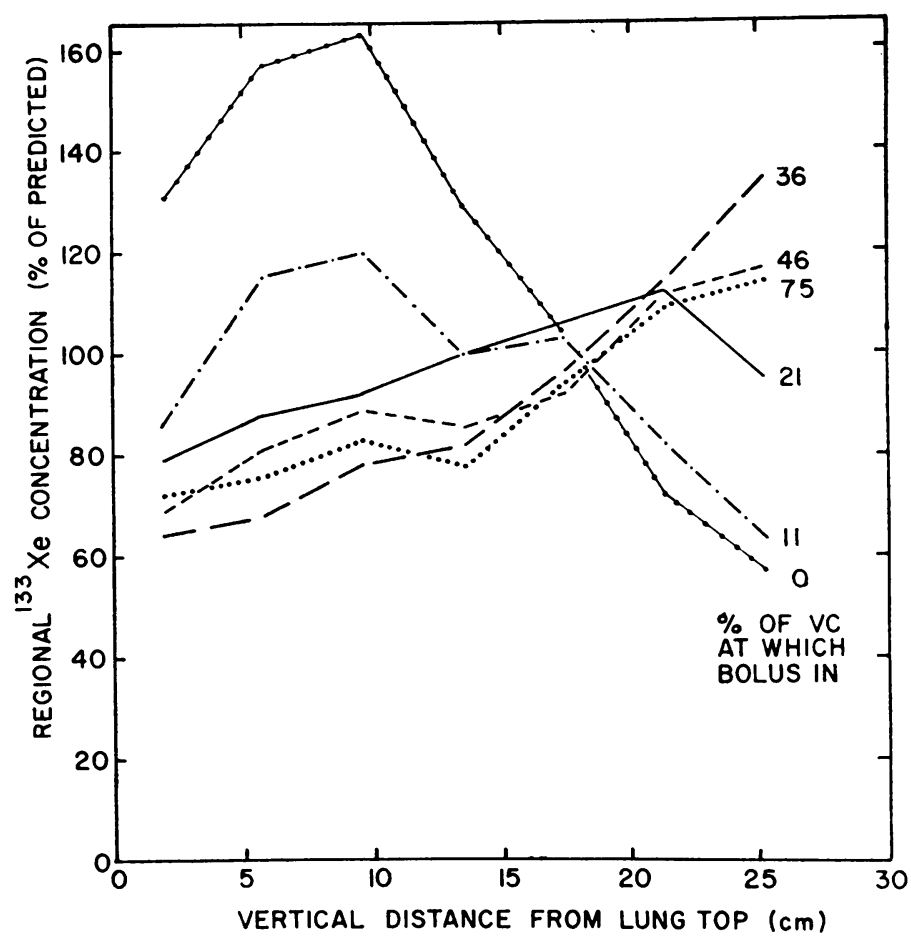

FIgURE 1 The percentage of the vital capacity (\% VC) at which the bolus was inhaled is shown for each curve. If the distribution of the bolus had been uniform throughout the lung, the regional concentration would have been $100 \%$ in all regions. Subject L.B.

sented for three different lung regions $(5,15$, and $25 \mathrm{~cm}$ from lung top). When the bolus was inhaled at $\mathrm{RV}$, most of it was distributed to the upper parts of the lungs, as shown by the higher ${ }^{133} \mathrm{Xe}$ concentration in these regions. Between RV and 65\% TLC, the proportion of the bolus distributed to the lower lung zones increases, reflecting progressive opening of closed airways in these regions $(4,9)$. Above $65 \%$ TLC, the regional ${ }^{133} \mathrm{Xe}$ concentration was shown to be virtually independent of the lung volume at which the bolus was inhaled, indicating that at $65 \%$ TLC all airways became open $(4,9)$. This lung volume will be referred to as the opening volume. It should be noted that in the six elderly subjects the FRC, which averaged 54\% TLC, was below the opening volume (Fig. $2 \mathrm{~A}$ ), whereas in young subjects the FRC was above the opening volume (Fig. 2 B). The data in Fig. 2 B were obtained on a group of five subjects whose age averaged $35 \mathrm{yr}$ (range : 29-42), whose FRC averaged $50 \%$ TLC, and in whom the opening volume averaged $45 \%$ TLC (9).
Concentration of ${ }^{183} \mathrm{Xe}$ in expired air. We recorded the concentration of ${ }^{133} \mathrm{Xe}$ in the expired gas after each bolus experiment as a function of expired volume. All such records showed the three phases in expired gas concentrations previously recognized (18): dead space gas $(I)$, mixed alveolar and dead space gas $(I I)$, and alveolar gas (III). In addition, in every experiment we found a definite and abrupt change in the slope of the so-called "alveolar plateau" toward the end of expiration when the bolus was inhaled near residual volume or above $65 \%$ TLC, i.e. when the regional differences in chest concentration of ${ }^{133} \mathrm{Xe}$ were most pronounced, as shown in Fig. $2 \mathrm{~A}$. This phase was previously noted in inert gas studies $(19,20)$ and in radioactive xenon studies on young subjects by Dollfuss et al. (9) who termed it phase IV. Results obtained in subject L.B. following a bolus given at $0 \% \mathrm{VC}$ and one at $75 \%$ $\mathrm{VC}$ are illustrated in Fig. 3. The corresponding regional concentrations preceding the expirations can be seen in Fig. 1. When the intrapulmonary 


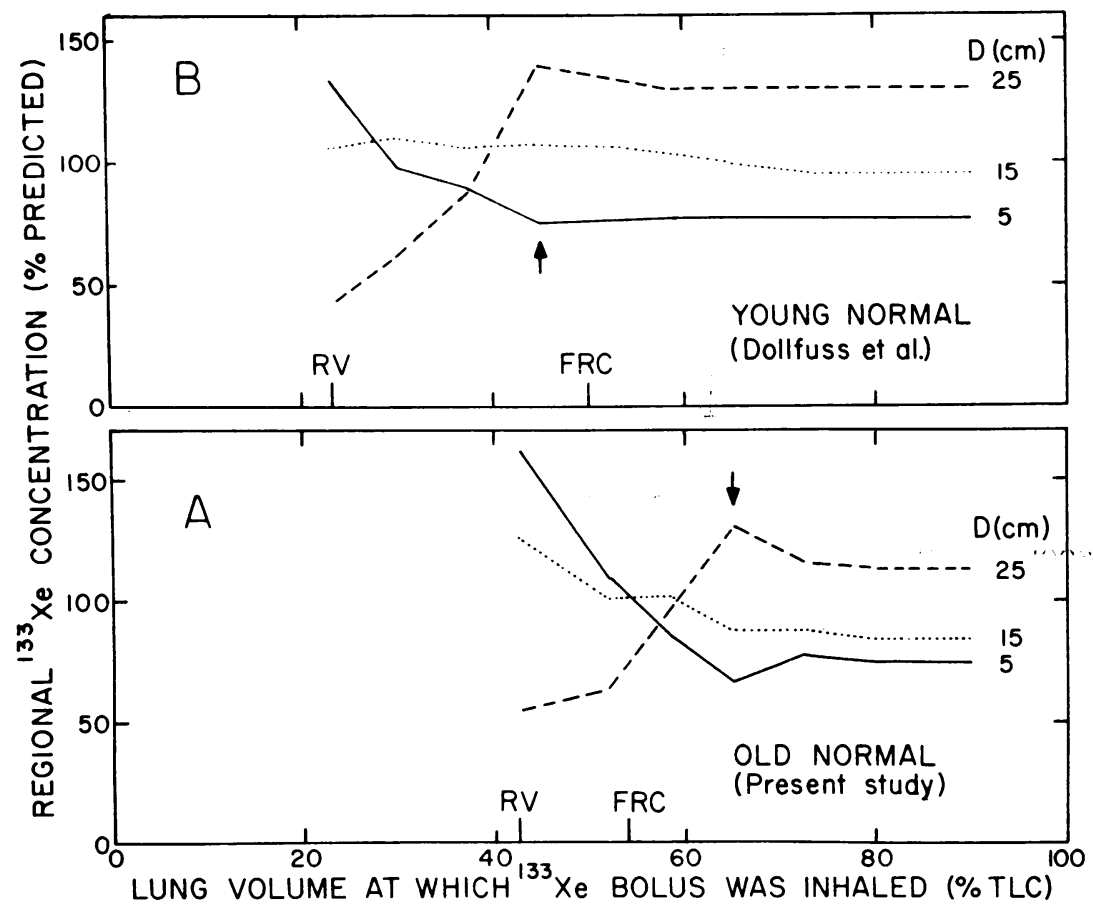

FigURE 2 Results from regions at vertical distance $(D)$ of 5,15 , and $25 \mathrm{~cm}$ from lung top are shown. Residual volume (RV) and functional residual capacity (FRC) are indicated. A : average results of 40 bolus experiments on six elderly subjects of present study; $B$ : average results of 40 bolus experiments on five young subjects by Dollfuss et al. (9). Arrows indicate opening volumes.

concentrations were greatest towards the apex (i.e. following bolus introduction at $\mathrm{RV}$ ), phase IV at first showed an increase in ${ }^{133} \mathrm{Xe}$ concentration followed by a slight decrease as RV was approached (Fig. $3 \mathrm{~A}$ ). On the other hand, phase IV demonstrated a progressive decrease when the preceding regional intrapulmonary concentration of ${ }^{133} \mathrm{Xe}$ was highest in dependent lung zones, i.e., following bolus introduction at $75 \% \mathrm{VC}$ (Fig. $3 \mathrm{~B}$ ). In both instances we can see that the junction between phases III and IV occurs at about the same lung volume, as it did in all bolus experiments in this subject. Similar results were obtained in all subjects. Dollfuss et al. (9) attributed the terminal change in concentration of the "alveolar plateau" (phase IV) to closure of airways, which starts in the most dependent parts of the lungs and moves upwards progressively as RV is approached. Thus, the lung volume corresponding to the junction between phases III and IV represents the lung volume at which the airways start to close. This volume will be referred to as the closing vol- ume. Table II lists this volume for each subject. In any one individual the closing volume showed little variation from one bolus experiment to another, regardless of the lung volume at which the bolus was inhaled. As shown in Table II, the closing volume was greater than FRC in all subjects except F.D. In young subjects, on the contrary, the closing volume was always well below FRC (9).

TABLE II

Closing Volumes and Functional Residual Capacities of Six Elderly Subjects

\begin{tabular}{|c|c|c|c|c|}
\hline \multirow[t]{2}{*}{ Subject } & \multicolumn{2}{|c|}{. Closing Volume } & \multicolumn{2}{|c|}{$\begin{array}{c}\text { Functional Residual } \\
\text { Capacity }\end{array}$} \\
\hline & $\% V C$ & $\% T L C$ & $\% V C$ & $\% T L C$ \\
\hline E.B. & 29 & 57 & 22 & 53 \\
\hline L.B. & 27 & 63 & 9 & 53 \\
\hline K.D. & 33 & 58 & 13 & 46 \\
\hline F.D. & 24 & 55 & 26 & 56 \\
\hline P.G. & 32 & 65 & 26 & 62 \\
\hline L.C. & 32 & 61 & 24 & 55 \\
\hline Mean & 30 & 60 & 20 & 54 \\
\hline
\end{tabular}




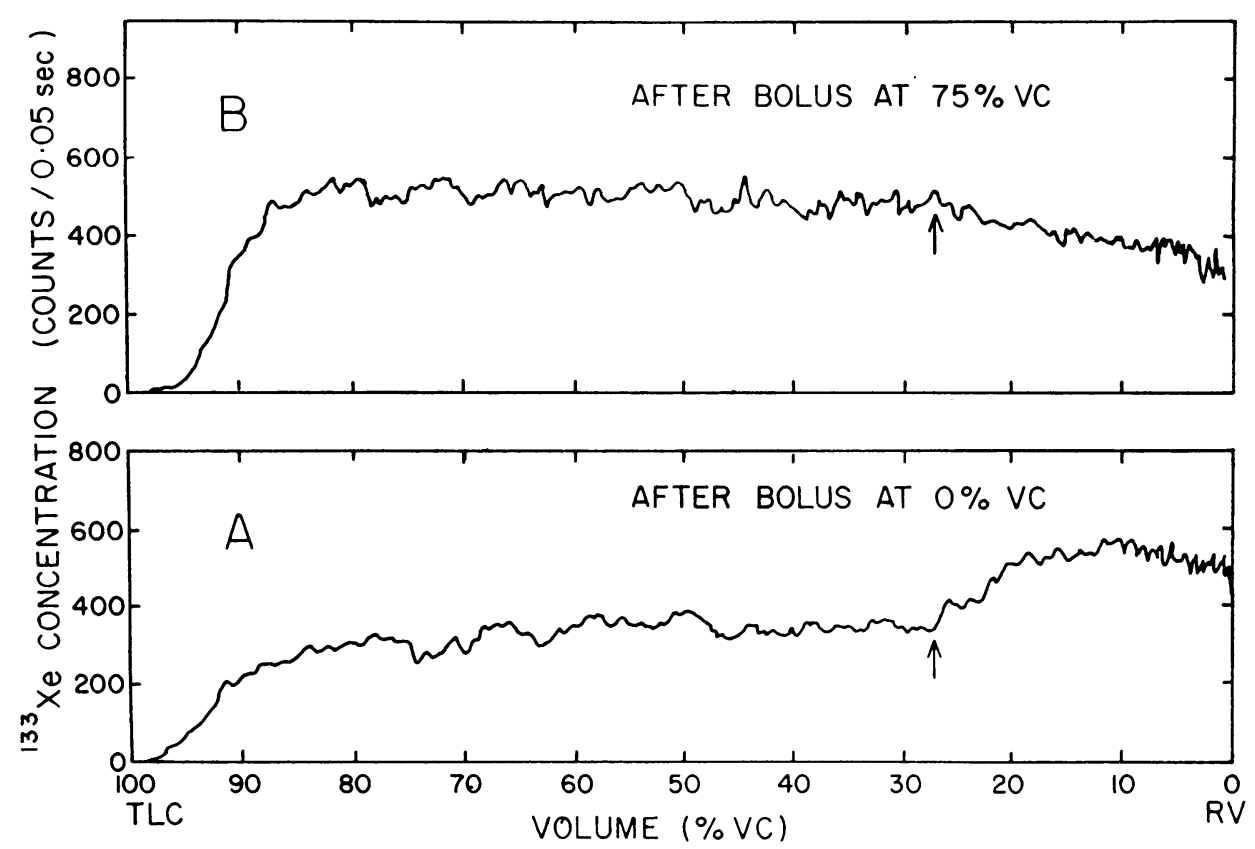

FIGURE 3 Relationship between ${ }^{133} \mathrm{Xe}$ concentration in expired air (counts/0.05 sec) and expired volume (\% VC) following an inspiratory vital capacity manoeuvre during which a bolus of ${ }^{133} \mathrm{Xe}$ was inhaled at $0 \% \mathrm{VC}(\mathrm{A})$ and at $75 \% \mathrm{VC}(\mathrm{B})$. At about $27 \% \mathrm{VC}$ the count rate demonstrated a marked increase in $\mathrm{A}$ and a decrease in $\mathrm{B}$. The oscillating pattern of the record is due to the random nature of radioactive decay and to cardiogenic artefact. Arrows indicate closing volume. Subject L.B.

In the six elderly subjects the opening volume, which averaged $65 \%$ TLC, was slightly higher than the closing volume, which averaged $60 \%$

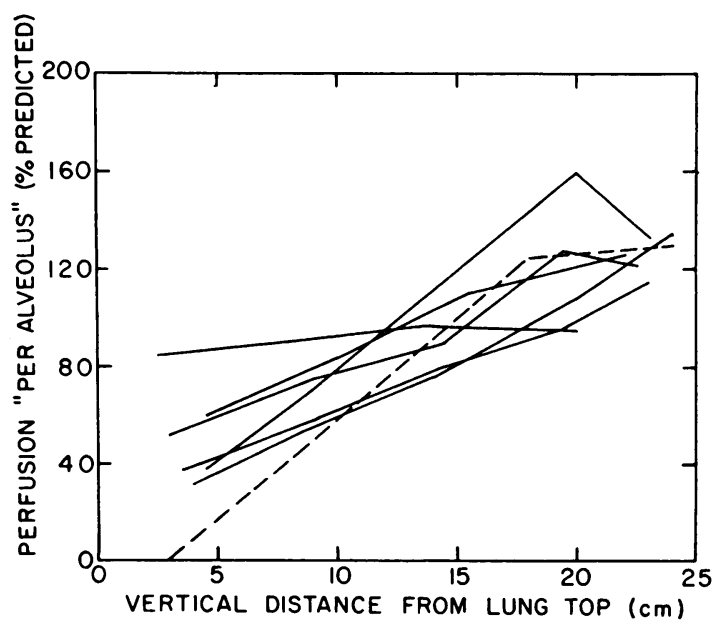

Figure 4 Solid lines: individual results on six elderly subjects; broken line: average results on six young subjects (16). If the distribution of perfusion "per alveolus" had been uniform throughout the lung, its value would have been $100 \%$ in all lung regions.
TLC. A similar difference was observed by Dollfuss et al. in young subjects.

Perfusion distribution. Fig. 4 shows the relationship between perfusion "per alveolus" and vertical distance down the lung in the six elderly subjects. Average results obtained on six young subjects by Anthonisen and Milic-Emili (16) are also shown for comparison. In all the older subjects, perfusion "per alveolus" to the upper lung zones was increased.

Static volume-pressure relations of lungs. Fig. 5 illustrates the average static volume-pressure relations of the lungs obtained in the elderly subjects (A) together with similar data obtained on five subjects whose age averaged $35 \mathrm{yr}$ (range: 29-42) (B). The latter were the same individuals used by Dollfuss et al. (9) in their ${ }^{133} \mathrm{Xe}$ bolus studies. Results obtained during lung deflation from TLC and inflation from RV are presented. Plotted on the curves are the opening and closing volumes. It can be seen that in the elderly subjects the static recoil pressures at any given lung volume were lower than in the younger individuals. This 

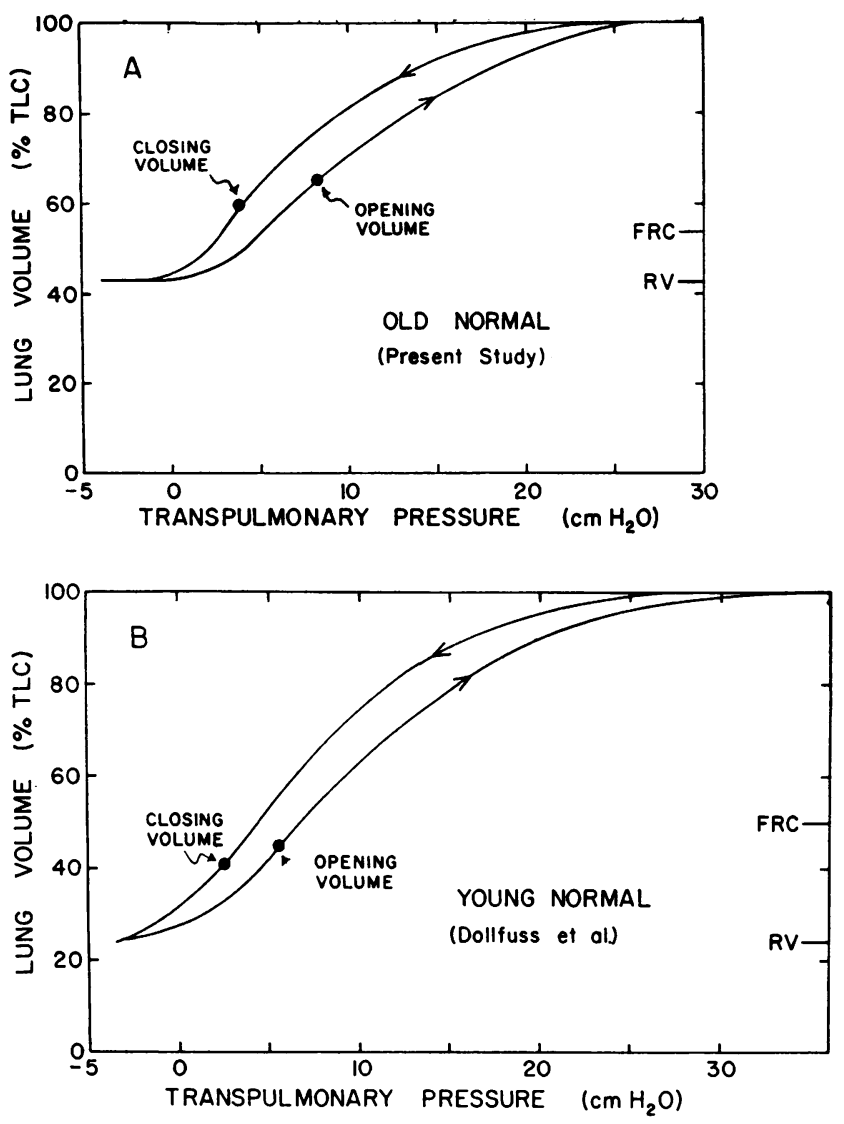

FIGURE 5 Average results on five elderly subjects of present study (A) and on five young subjects of Dollfuss et al. (9) (B). Closing and opening volumes, and RV and FRC are indicated. finding agrees with the result of previous studies (11).

\section{DISCUSSION}

In all six elderly subjects of the present study the regional distribution patterns of inspired ${ }^{133} \mathrm{Xe}$ boluses and the expired ${ }^{133} \mathrm{Xe}$ concentration patterns were basically similar to those observed by Dollfuss et al. (9) on younger men. In line with our predictions, however, we found that in the elderly subjects the closing and opening volumes were consistently higher than in the younger individuals. This discrepancy results in part from loss of elastic recoil with age (Fig. 5). This loss, however, is not the sole cause of the increase in closing and opening volumes observed in the elderly subjects. If loss in lung elastic recoil were the only cause of the increased closing and opening volumes with age, the transpulmonary pressures at which the airways open and close would be the same in both old and young subjects. This, however, is not the case. Indeed, using the results of the present study, a rough estimate of the transpulmonary pressure at which the airways begin to close (closing pressure) can be made as follows. As shown in Fig. 5, the static transpulmonary pressure at the closing volume amounts to $3.7 \mathrm{~cm}$ $\mathrm{H}_{2} \mathrm{O}$ in the elderly and $2.5 \mathrm{~cm} \mathrm{H}_{2} \mathrm{O}$ in the young subjects. These pressures, as determined with the esophageal balloon method, reflect the transpulmonary pressures near the mid-level down the lungs (8). Accordingly, assuming a vertical lung length of $30 \mathrm{~cm}$ and a vertical pleural pressure "gradient" of $0.25 \mathrm{~cm} \mathrm{H} \mathrm{H}_{2} \mathrm{O} / \mathrm{cm}$ descent (21), it can be calculated that in elderly subjects the transpulmonary pressure at the closing volume in the most dependent lung zones is close to zero whereas in the younger individuals the corresponding value is $-1.25 \mathrm{~cm} \mathrm{H}_{2} \mathrm{O} .{ }^{1}$ Thus, according to these estimates, the closing pressure is about zero in elderly subjects and about $-1.25 \mathrm{~cm} \mathrm{H}_{2} \mathrm{O}$ in younger

1 A negative transpulmonary pressure indicates that pleural pressure exceeds airway pressure. 
individuals. The latter value is in close agreement with the results of Cavagna et al. (10) who reported that in animals the airways begin to collapse at a transpulmonary pressure of $-2 \mathrm{~cm} \mathrm{H} \mathrm{H}_{2} \mathrm{O}$. Similarly, the opening pressure (the transpulmonary pressure at the base of the lung at the opening volume) can be estimated to be $4.5 \mathrm{~cm}$ $\mathrm{H}_{2} \mathrm{O}$ in the elderly and $1.8 \mathrm{~cm} \mathrm{H}_{2} \mathrm{O}$ in the younger subjects. The latter value agrees with the results of Burger et al. (unpublished observations). Although these estimates of absolute closing and opening pressures are only tentative because the magnitude of the vertical pleural pressure "gradient" is not precisely known, the difference between opening and closing pressure is presumably valid. This difference amounted to $4.5 \mathrm{~cm} \mathrm{H}_{2} \mathrm{O}$ in the elderly and $3.0 \mathrm{~cm} \mathrm{H}_{2} \mathrm{O}$ in the younger subjects.

It is of interest to note that although the differences between opening and closing pressures are large in both old and young individuals, the differences in opening and closing volumes are relatively small (Fig. 5). These differences are due to the static volume-pressure hysteresis of the lungs, i.e., the greater inflation pressures at any given lung volume necessarily result in decreased opening volume. Clearly, in the absence of hysteresis there would be a much larger discrepancy between the opening and closing volumes.

Our results indicate that in elderly subjects both the opening and closing pressures are increased. These differences between young and old are presumably valid for the reasons stated above. For opening pressure this difference averaged $2.7 \mathrm{~cm}$ $\mathrm{H}_{2} \mathrm{O}$ and for closing pressure $1.2 \mathrm{~cm} \mathrm{H}_{2} \mathrm{O}$. This change with age indicates that loss of lung elastic recoil is not the sole cause of the increase in opening and closing volumes; the increase in opening and closing volumes with age is due in part to increased opening and closing pressures, respectively.

The reasons for the increased opening and closing pressures of the aged airways must remain speculative in light of present knowledge. The pressure required to open a closed airway will depend on the interaction of several factors, such as: (a) The diameter of the airway involved and the surface tension of the liquid lining it. From the Laplace relationship, the smaller the diameter and the greater the surface tension, the larger will be the opening pressure. (b) The airway wall could conceivably operate either to open the airway or to close it. Cavagna, Stemmler, and Duloois (10) have shown that, in the intact animal, the airways resist closure until the transpulmonary pressures are negative, i.e., they tend to recoil outward. One might expect the smooth muscle tone in the airways to operate in the opposite direction. Olsen et al. (22) however found that the bronchi resist collapse more when the smooth muscle is constricted. It thus seems likely that the airway wall would operate to reduce rather than to increase the opening pressure. (c) The manner in which pleural pressure is transmitted to the outer wall of the airway via the elastic elements of the lung also affects the opening pressure. Similar considerations apply to the increase in closing pressure. Clearly, it is impossible at present to make any definite conclusions concerning which factors change with age.

In five out of six elderly subjects airway closure in dependent lung zones was present at FRC, whereas in young subjects it occurs only at lung volumes well below FRC (9). Furthermore, our results indicate that in the elderly subjects during lung inflation lower zone airway closure persists up to lung volumes of about $65 \%$ TLC; the difference between the latter volume and FRC averages about $11 \%$ TLC $(\approx 700 \mathrm{ml})$. Since in sul $)$ jects of similar age the resting ticlal volume averages about $380 \mathrm{ml}$ (23), it follows that in most elderly subjects some of the dependent lung units are closed either throughout or during part of the resting breathing cycle; hence ventilation is not distributed preferentially to lower lung zones as in normal young men. ${ }^{2}$ In only one of our elderly subjects (F.D.) was airway closure absent at FRC; hence the distribution of resting ventilation was preferential to the lower lung zones. It is of interest to note that this subject had greater static lung recoil pressures than the rest of the group.

The presence of lower zone airway closure during resting ventilation in the elderly subjects is

2 Some airways may attain the opening pressure at the beginning of inspiration, while others may only open towards the end of inspiration, i.e., when pleural pressures are most negative. Similarly, some airways may reach the closing pressure at the beginning of expiration while others will close only towards the end of expiration, i.e., when pleural pressures are most positive. 
significant not only because of its effect on regional distribution of ventilation, but also because it helps to explain the results obtained previously with inert gas methods. Sandqvist and Kjellmer (24), using a single breath method, reported increased unevenness of ventilation with age. First they had the subject inspire 1 liter of oxygen from FRC, and then they measured the difference in nitrogen concentration between expired volumes of $750 \mathrm{ml}$ and $1250 \mathrm{ml}$. It should be noted that while in young subjects both of these points would be within phase III of the "alveolar plateau," in the elderly at least the second point (which is below FRC) would fall within phase IV. Thus we see that the $\mathrm{N}_{2}$ concentration difference measured must increase in the aged subjects. Similarly, the fact that in elderly subjects airway closure is present in the tidal volume range may also explain in part the reported decrease with advancing age in mixing efficiency (25) and delay in nitrogen clearance (26-29). In elderly subjects resting ventilation takes place in the range of lung volumes at which the extent of airway closure varies with lung volume (Fig. 2). Therefore, the regional distribution of ventilation would also be affected by relatively small changes in tidal volume and/or preinspiratory volume which may occur with changes in posture, apprehension, etc. This probably explains the considerable variability of the results reported in elderly subjects with inert gas methods. It should also be noted that in the range of lung volumes at which airway closure is present, the distribution of inspired gas is markedly affected by speed of inspiration (Anthonisen, unpublished observations). By contrast, at lung volumes at which airway closure is absent, ventilation distribution appears to be much less dependent on the breathing pattern. Finally, the presence of lowerzone airway closure during resting tidal ventilation in the elderly subjects would lead to the exclusion of some alveolar gas from inert gas dilutions used in measuring the FRC. Indeed, we measured the FRC in the elderly subjects using the closed circuit helium dilution method and found that the average FRC measured with this method was about 0.3 liters lower than the corresponding value obtained with the body plethysmograph.

Previous measurements of regional distribution of perfusion on young subjects have shown that blood flow is absent in the uppermost parts of the lung when the subject is at rest (16). The present results indicate that in the elderly subjects the upper parts of the lung are better perfused than in the young individuals. This increase in apical blood flow is presumably due to a rise in pulmonary artery pressure with age which is probably associated with increased lower zone vascular resistance resulting from loss of elastic recoil of the lungs (30).

From regional ventilation and perfusion data it is possible to estimate the regional ventilation-toperfusion distribution, i.e., the regional $\dot{V} / \dot{Q}$. Because of the marked influence of small changes in tidal volume and/or FRC on ventilation distribution in our elderly subjects, their regional $\dot{\mathrm{V}} / \dot{Q}$ distribution must be critically dependent on their breathing pattern; and hence $\dot{V} / \dot{Q}$ could not be adequately, described by a single number. Indeed, a small increase in tidal volume and/or FRC will result in an increased $\dot{V} / \dot{Q}$ in the dependent lung zones. Our results, however, indicate that in elderly subjects during resting ventilation the $\dot{V} / \dot{Q}$ in the dependent lung zones must be considerably lower than in young individuals. This is probably one of the factors causing the observed decrease in arterial oxygen tension in aged subjects $(12,13)$. It should be noted that in all of our elderly subjects the perfusion to the upper parts of the lungs was increased. This increased regional perfusion somewhat reduces the degree of $\dot{V} / \dot{Q}$ abnormality which would otherwise be greater. Also, it should be noted that although results obtained with external counters reflect the over-all $\dot{V} / \dot{Q}$ distribution of different lung regions, these results fail to detect differences that may exist within each region. Since the lower lung zones of elderly subjects presumably contain both open and trapped units during quiet breathing, the $\dot{V} / \dot{Q}$ abnormality (and hence the impairment of gas exchange) may well be greater than the present technique has revealed.

Airway closure in lower lung zones during resting breathing has been observed in obese subjects (31) in whom it probably also contributes to increased alveolar-arterial differences in oxygen tension. In the obese subjects, however, the increase is caused by reduction in FRC resulting from obesity, rather than by a loss in the elastic recoil properties of the lungs. Clearly, in terms of regional distribution of ventilation and perfusion 


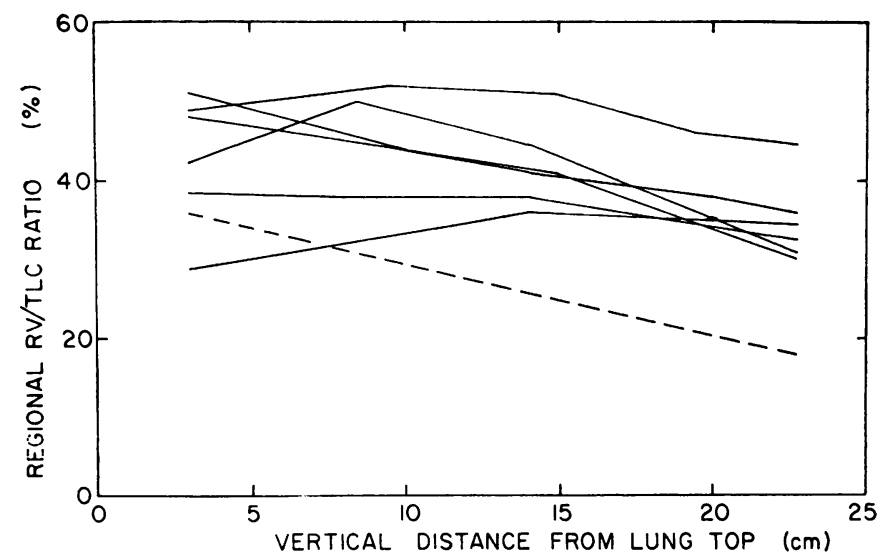

Figure 6 Solid lines: individual results on six elderly subjects. Broken line: average results on seven subjects whose age averaged 35 yr (range: 29-35) (4).

in the lungs, the effects of loss of elastic recoil and of obesity are additive, and one would expect to find larger $\mathrm{A}-\mathrm{a} \mathrm{O}_{2}$ differences in elderly obese patients than in elderly slim subjects.

The results of the present studly are also of interest in relation to a venerable question: What limits maximal expiration in elderly subjects? Two main mechanisms have been proposed: $(a)$ airway collapse in which the residual volume reflects the volume of gas trapped behind the collapsed airways (32), and $(b)$ neuromuscular limit in which the residual volume is determined by a balance between the force developed by the expiratory muscles and the opposing forces, such as the elastic recoil of the respiratory system and the antagonistic activity of the diaphragm (33). In young subjects both mechanisms are involved; expiration in the dependent lung zones is limited by airway closure, whereas expiration in the upper lung zones proceeds until a balance is reached between the force of the expiratory muscles and the opposing forces (4). In elderly stubjects, on the contrary, airway closure appears to limit expiration throughout the lungs. Indeed, in the elderly subjects, following an early bolus, phase IV first showed an increase in ${ }^{133} \mathrm{Xe}$ concentration and then showed a decrease in concentration as $\mathrm{RV}$ was approached (Fig. $3 \mathrm{~A}$ ). The initial increase probably reflects a rising level of airway closure up the lungs and hence a predominant contribution to the expirate from the upper and middle lung zones where the ${ }^{133} \mathrm{Xe}$ concentration is higher than in dependent zones (Fig. 1). The terminal decrease in expired ${ }^{133} \mathrm{Xe}$ concentration indicates that as RV is approached airway closure has progressed above the lung level of highest ${ }^{133} \mathrm{Xe}$ concentration (i.e. above about $10 \mathrm{~cm}$ from the lung top). Thus, these results suggest that in elderly subjects expiration may be limited almost entirely by airway closure. ${ }^{3}$ In young subjects, on the contrary, Dollfuss et al. (9) observed that, following an early bolus, the ${ }^{133} \mathrm{Xe}$ concentration in phase IV rose progressively until $\mathrm{RV}$ was reached. Since the regional ${ }^{123} \mathrm{Xe}$ concentration in young subjects was also highest, about $10 \mathrm{~cm}$ from the lung top, the results of Dollfuss et al. suggest that the airway closure at RV in young subjects has not progressed into the upper $10 \mathrm{~cm}$ of the lungs. These results indicate that the maximal expiration of young subjects is not limited entirely by airway closure. These conclusions are supported by the findings of Leith and Mead (34). They studied five healthy stibjects over the age of $40 \mathrm{yr}$ and five under the age of $35 \mathrm{yr}$. These subjects were seated within a chamber, sealed about the neck, and instructed to perform forced expiratory vital capacity ma-

${ }^{3}$ Following boluses inhaled at high lung volumes the regional ${ }^{188} \mathrm{Xe}$ concentration always decreased progressively from lung bottom to top (Fig. 1). Accordingly, it is not surprising that during subsequent expiration phase IV demonstrated a continuous decrease in ${ }^{139} \mathrm{Xe}$ concentration until RV was reached (Fig. $3 \mathrm{~B}$ ), i.e., progressive closure of airways up the lung during expiration would be expected to result in continuous increase in expired ${ }^{193} \mathrm{Xe}$ concentration even if the closure eventually progressed up to the lung top. 
noeuvres. As flow either neared or reached zero, the pressure in the chamber was abruptly raised to $40 \mathrm{~cm} \mathrm{H}_{2} \mathrm{O}$. Little response was seen in the older group, but flow rose sharply in the younger subjects. This finding suggests that in the younger group residual volume is, at least in part, determined by the balance between maximum expiratory muscle force and total recoil forces of the respiratory system. Hence, if expiration is assisted, lung volume can be reduced below $\mathrm{RV}$. In contrast, the smaller response to assisted expiration in the older group suggests that in these subjects maximum expiration is limited mainly by airway compression. To further test this hypothesis, using the ${ }^{133} \mathrm{Xe}$ method previously described (4) we have measured the regional $\mathrm{RV} / \mathrm{TLC}$ ratios at various vertical levels of the lungs in six elderly subjects. The results are shown in Fig. 6, together with similar data of seven young men (4). In the seven young subjects, regional RV/TLC ratio is considerably greater in upper than in lower lung zones. This difference again suggests that in upper zones maximal expiration is not limited by airway closure. In the elderly group, on the other hand, if maximal expiration is limited by airway closure throughout the lung, regional $\mathrm{RV} / \mathrm{TLC}$ ratios ought to be more uniform. Indeed, in the six elderly subjects the regional $R V / T L C$ ratio was found to be much more uniform than in the seven younger subjects, as shown in Fig. 6.

The results of the present study are of general interest in relation to the difficult problem of the biology of aging. It is clear that ventilation distribution within the lung is affected by the changes in the mechanical properties of the aging lung. Although both histological and histochemical changes have been reported in the aged lung (11) the cause of these changes is not precisely understood. However, it is interesting to note the internal consistency of the present data in respect to subject F.D., who was the only elderly subject in whom the airways began to close at lung volumes lower than FRC. He not only had the greatest lung elastic recoil pressures of the entire group studied, but he also demonstrated values above the predicted normal values in almost every aspect of lung function measured (Table I). In other words, for some unknown reason, in this man the aging process of the lungs has probably been slower than in the other individuals.

\section{ACKNOWLEDGMENTS}

This work was supported in part by grants from The John A. Hartford Foundation and The Medical Rescarch Council of Canada.

\section{REFERENCES}

1. West, J. B., and C. T. Dollery. 1960. Distribution of blood flow and ventilation-perfusion ratio in the lung, measured with radioactive $\mathrm{CO}_{\text {.. }}$ J. Appl. I'hysiol. 15: 405.

2. Ball, W. C., Jr., P. B. Stewart, L. G. Newsham, and D. V. Bates. 1962. Regional pulmonary function studied with xenon ${ }^{133}$. J. Clin. Invest. 41: 519.

3. Bryan, A. C., L. G. Bentivoglio, F. Beerel, H. MacLeish, A. Zidulka, and D. V. Bates. 1964. Factors affecting regional distribution of ventilation and perfusion in the lung. J. Appl. Physiol. 19: 395.

4. Milic-Emili, J., J. A. M. Henderson, M. B. Dolovich, D. Trop, and K. Kaneko. 1966. Regional distribution of inspired gas in the lung. J. Appl. Phy'siol. 21: 749.

5. Krueger, J. J., T. Bain, and J. L. Patterson, Jr. 1961. Elevation gradient of intrathoracic pressure. J. Appl. Phy'siol. 16: 465.

6. Turner, J. M. 1962. Distribution of lung surface pre:ssure as a function of posture in dogs. Physiologist. 5: 223.

7. Daly, W. J., and S. Bondurant. 1963. Direct measurement of respiratory pleural pressure changes in normal man. J. Appl. Physiol. 18: 513.

8. Milic-Emili, J., J. Mead, and J. M. Turner. 1964 Topography of esophageal pressure as a function of posture in man. J. Appl. Physiol. 19: 212.

9. Dollfuss, R. E., J. Milic-Emili, and D. V. Bates. 1967. Regional ventilation of the lung studied with boluses of ${ }^{133}$ xenon. Resp. Physiol. 2: 234.

10. Cavagna, G. A., E. J. Stemmler, and A. B. Dubois. 1967. Alveolar resistance to atelectasis. J. Appl. Physiol. 22: 441.

11. Radford, E. P., Jr. 1964. Static mechanical properties of lungs in relation to age. In Aging of the Lung. L. Cander, editor. Grune \& Stratton, Inc., New York. 152-155.

12. Raine, J. M., and J. M. Bishop. 1963. A-a difference in $\mathrm{O}_{2}$ tension and physiological dead space in normal man. J. Appl. Phy'siol. 18: 284.

13. Mellemgaard, K. 1966. The alveolar-arterial oxygen difference: Its size and components in normal man. Acta Physiol. Scand. 67: 10.

14. Mead, J. 1960. Volume displacement body pletlyysmograph for respiratory measurements in human subjects. J. Appl. Physiol. 15: 736.

15. Bates, D. V., and R. V. Christie. 1964. Respiratory function in disease. An Introduction to the Integrated Study of the Lung. W. B. Saunders Co., Philadelphia. 92-93.

16. Anthonisen, N. R., and J. Milic-Emili. 1966. Distribution of pulmonary perfusion in erect man. J. Appl. Physiol. 21: 760. 
17. Milic-Emili, J., J. Mead, J. M. Turner, and E. M. Glauser. 1964. Improved technique for estimating pleural pressure from esophageal balloons. J. Appl. Physiol. 19: 207.

1s. Fowler, W. S. 1952. Intrapulmonary distribution of inspired gas. Physiol. Rev. 32: 1.

19. Fowler, W. S. 1949. Lung function studies. III. Uneven pulmonary ventilation in normal subjects and in patients with pulmonary disease. J. Appl. Physiol. 2: 283.

20. Read, J. 1966. Alveolar populations contributing to expired gas tension plateaus. J. Appl. Physiol. 21: 1511.

21. Bryan, A. C., J. Milic-Emili, and D. Pengelly. 1966. Effect of gravity on the distribution of pulmonary ventilation. J. Appl. Physiol. 21: 778.

22. Olsen, C. R., A. E. Stevens, and M. B. McIlroy. 1967. Rigidity of tracheae and bronchi during muscular constriction. J. Appl. Physiol. 23: 27.

23. D. S. Dittmer and R. M. Grebe, editors. 1958. Handbook of Respiration. W. B. Saunders Co., Philadelphia.

24. Sandqvist, L., and I. Kjellmer. 1960. Normal values for the single breath nitrogen elimination test in different age groups. Scand. J. Clin. Lab. Invest. 12: 131.

25. Bates, D. V., and R. V. Christie. 1950. Intrapulmonary mixing of helium in health and in emphysema. Clin. Sci. 9: 17 .

26. Cohen, A. A., A. Hemingway, and C. Hemingway. 1959. Standardization of the pulmonary nitrogen clear- ance test using older normal men. J. Lab. Clin. Med. 54: 603.

27. Robertson, J. S., W. E. Siri, and H. B. Jones. 1950. Lung ventilation patterns determined by analysis of nitrogen elimination rates; use of the mass spectrometer as a continuous gas analyzer. J. Clin. Invest. 29: 577.

28. Georg, J. 1955. The nitrogen clcarance of the lungs. Scand. J. Clin. Lab. Invest. 7: 308.

29. Greifenstein, F. E., R. M. King, S. S. Latch, and J. H. Comroe, Jr. 1952. Pulmonary function studies in healthy men and women 50 years and older. J. Appl. Physiol. 4: 641 .

30. Hughes, J. M. B., J. B. Glazier, J. E. Maloney, and J. B. West. 1967. Effect of interstitial pressure on pulmonary blood flow. Lancct. 1: 191.

31. Holley, H. S., J. Milic-Emili, M. R. Becklake, and D. V. Bates. 1967. Regional distribution of pulmonary ventilation and perfusion in obesity. J. Clin. Invest. 46: 475.

32. Slagter, B., and H. Heemstra. 1955. Limiting factors of expiration in normal subjects. Acta Physiol. Pharmacol. Neerl. 4: 419.

33. Agostoni, E., and G. Torri. 1962. Diaphragm contraction as a limiting factor to maximum expiration. $J$. Appl. Physiol. 17: 427.

34. Leith, D. E., and J. Mead. 1964. Flow and volume events near residual volume during forced vital capacity manoeuvres. Phy'siologist. 7: 189. 